\title{
Traduçấo
}

\section{SOBRE A CIÊNCIA FÍSICA E A CIÊNCIA METAFÍSICA ${ }^{1}$}

\section{Al-Fārābi}

Introdução, tradução e notas de Jamil Ibrahim Iskandar ${ }^{2}$.

\section{INTRODUÇÃo}

Al-Fārābīi foi um destacado filósofo de sua época, sobretudo por seu conhecimento, interesse e comentários sobre a filosofia de Platão e de Aristóteles e, também, por seu talento filosófico. Em seu tempo havia muito interesse pela filosofia grega antiga, e o mundo islâmico se encontrava no auge das traduçóes da filosofia clássica antiga. Como exemplo, podemos mencionar a obra de al-Fārābī denominada $O$ livro da concordância entre as ideias dos dois filósofos ${ }^{4}$, Platão, o divino, e Aristóteles (Kitāb al-jam' bayn ra'iyay al-ḥakimain, aflațon al-ilāhì e aristuțālis). Esta obra era ímpar quando foi escrita; não havia absolutamente nada igual e, por isto, tem uma importância histórica deveras relevante em

1 "Ciência física" e "ciência metafísica" traduz 'Ilm al-Țabì ‘̀ e 'Ilm al-Ilāhī, respectivamente. O termo "ciência” é utilizado aqui como sinônimo de conhecimento. Assim sendo, pode-se dizer que al-Fārābī anuncia uma exposição sobre o conhecimento da física (ciência natural) e sobre o conhecimento da metafísica.

2 Professor de Filosofia Medieval Árabe na Universidade Federal de São Paulo (Unifesp), Guarulhos, SP - Brasil. (D) https://orcid.org/0000-0001-8336-654X E-mail: jamil.iskandar@yahoo.com.br

${ }^{3}$ Al-Fārābī, ou Abu Nașr Muhammad ben Muhammad Ṭarjān ben Uzlug al-Fārābī. Nasceu na cidade de Fārāb, na Transoxiana, onde hoje é o Uzbequistão. Não se conhece exatamente a data de seu nascimento, mas pelo ano de sua morte, deduz-se com segurança a data de seu nascimento, pois, para isto, tem-se registros confiáveis. Assim sendo, é mais seguro afirmar que nasceu por volta de 870 e morreu em 950, em Damasco, onde encontra-se sepultado. Devido ao seu enorme talento como filósofo, ficou conhecido como o Segundo Mestre (Al-Mu'alim al-Tāni), sendo Aristóteles, para os árabes, o Primeiro Mestre (Al-Mu'alim al-Awal).

4 "Filósofos" traduz o termo árabe hakīmayn (pode ser filósofos ou sábios).

http://dx.doi.org/10.1590/0101-3173.2019.v42esp.19.p391

This is an open-access article distributed under the terms of the Creative Commons Attribution License. 
função dos textos colocados à disposição dos estudiosos para conhecer com certa profundidade a filosofia tanto de Platáo como de Aristóteles.

Nela são tomados os textos de Platão e Aristóteles que parecem contraditórios, transcrevendo-os literalmente, com indicação do livro e capítulo do qual foram tomados. Alguns dos referidos textos são quase irreconhecíveis, mas pela simples razão de que assim eram na tradução árabe ou porque eram considerados obras aristotélicas, pois algumas das quais passavam como tais. Os textos de Platão correspondiam ao Fédon, o Político, a República, o Timeu e a Carta VII; os de Aristóteles pertencem à Metafísica, Primeiros e Segundos Analiticos, De Anima e Ética Nicomaqueia e, ainda, a Teologia do Pseudo-Aristóteles, ou seja, Plotino (CRUZ HERNANDEZ, 1996, p. 180). Al-Fārābī julgou não haver discrepância entre a filosofia de Platão e Aristóteles, e se alguém pensa o contrário, então, não conheceu corretamente o pensamento deles ou é ignorante a respeito de suas doutrinas.

O nosso filósofo se notabilizou pelas explicações que apresentou das obras de Aristóteles. Para citar apenas um exemplo, vejamos um fato ocorrido com Ibn Sīnā (Avicena):

Leu 40 vezes a Metafisica de Aristóteles, até sabê-la de cor, e não entendeu nada do conteúdo nem o objetivo da obra. Mas certo dia, ao passar por um mercado, um homem lhe ofereceu um pequeno livro. A princípio Avicena não se interessou. No entanto, dada a insistência do vendedor, acabou comprando-o: era o livro de al-Fārābī Sobre o objetivo da Metafísica de Aristóteles. De imediato Avicena foi para casa e leu a pequena obra. A partir daí, então, entendeu a Metafisica de Aristóteles. "Fiquei contente com isto", afirmou Avicena. No outro dia distribuiu esmolas aos pobres para agradecer a Deus pelo ocorrido. (ISKANDAR, 2005, p. XXIV).

Ademais, a filosofia escrita em árabe tem em al-Fārābī o primeiro filósofo sistemático, isto é, que estabeleceu uma ordenação para filosofar; nos legou diversas obras em distintos temas, notadamente, as que versam sobre política e o convívio em sociedade. É considerado o fundador do neoplatonismo e da filosofia política no mundo islâmico. Inspirado na cosmologia e metafísica de Plotino e Próclo, al-Fārābī elaborou um esquema emanacionista para explicar a procedência dos seres a partir do ser primeiro, Deus. Inspirado na República de Platáo, elaborou uma obra inédita no meio islâmico, ou seja, $A$ cidade virtuosa (al-Madīna al-Fāẹila) que, segundo al-Fārābī, é o lugar em que as pessoas podem adquirir a felicidade quando tal cidade é governada por um Guia (Imã) e este Guia é o filósofo, pois "a ciência política se ocupa primeiramente da felicidade [...] Também se ocupa das açóes, modos de viver, 
qualidades morais, costumes e hábitos voluntários.” (AL-FĀRĀBĪ, 2017, p. 26). "A ciência política consiste no conhecimento das coisas por meio das quais os habitantes das cidades alcancem a felicidade através das associaçóes políticas." (AL-FĀRĀB̄̄, 2017, p. 26).

O interesse aqui é o de apresentar uma tradução direta do árabe do capítulo IV de uma célebre obra de al-Fārābī, ou seja, $O$ catálogo das ciências (Iḥ̂ă' al-'Ulūm),cujo capítulo apresenta uma exposição dos objetivos e divisões da ciência natural (física) e da metafísica. Nesta obra, nosso filósofo se propôs a catalogar as ciências conhecidas em sua época, o séc. X. O editor, Ali Bu Melḥem, edição de Beirut de 1996, que aqui utilizamos, foi publicada em 1880 na cidade de Istambul; em 1931, no Cairo; em 1932, em Madri e em 1960, em Glasgow. O editor menciona, ainda, a preservação de quatro manuscritos: um em Najaf, no Iraque; um na Índia, um em Escorial (Espanha), e um em Princeton (USA).

Al-Fārābī dividiu seu livro em cinco capítulos abrangendo os seguintes conhecimentos: a) ciência da linguagem; b) ciência da lógica; c) ciências das matemáticas; d) ciência da natureza e metafísica; e, por último, e) ciência política, ciência da jurisprudência e ciência da teologia ${ }^{5}$. E desmembra cada capítulo em subtemas. Vejamos esta divisão no prelúdio do editor ${ }^{6}$ :

\section{Prelúdio}

\section{EM NOME DE DEUS, O MISERICORDIOSO, O MISERICORDIADOR ${ }^{7}$}

Livro de Abi Nașr Muḥammad ben Muhammad al-Fārābīi ${ }^{8}$, sobre a hierarquia das ciências. Ele disse?: neste livro, nossa intenção é catalogar as ciências mais conhecidas, ciência por ciência, e fazer conhecer a totalidade que cada uma delas abrange e as partes de cada uma que tem partes e, também, a totalidade do que há nas partes. Dividimos (o livro) em cinco capítulos: 10)

\footnotetext{
${ }^{5}$ Al-Fārābī escreve exatamente dessa maneira, ou seja: ciência da linguagem, ciência da lógica, ('Ilm al-lisān, 'Ilm al-manțiq), etc.

${ }^{6}$ Traduzo aqui o prelúdio de Ihṣā' al- 'Ulūm, apresentado pelo editor árabe de Beirute (AL-FĀRĀBĪ. Iḥ̣ă 'al- 'Ulūm. Ediçâo, apresentaçẫo, comentário explicativo e divisão dos capítulos de Ali Bu Melhem. Beirute: Dār al-Hilāl, 1996).

${ }^{7}$ É com esta frase que o editor inicia o prólogo, como é costumeiro entre os praticantes da religião muçulmana.

${ }^{8}$ Seguimos tal como o editor escreveu o nome de al-Fārābī.

9 "Ele disse": esta expressão, afirma o editor, não é de al-Fārābī; provavelmente é do copista do manuscrito.
} 
Sobre a ciência da linguagem e suas partes; $2^{\circ}$ ) Sobre a ciência da lógica e suas partes; $3^{\circ}$ ) Sobre a ciência das matemáticas, as quais abrangem: os números, a geometria, ciência dos observatórios, astronomia, ciência da música, ciência dos pesos e medidas e ciência das mecânicas; $4^{\circ}$ ) Sobre a ciência da natureza (a física) e suas partes, e ciência da metafísica e suas partes; 50) Sobre a ciência política e suas partes, sobre a ciência da jurisprudência e a ciência da teologia. A pessoa se beneficiará deste livro se pretender [conhecer] uma dessas ciências e especular a respeito da mesma; saber o que esta [ciência] oferece, sobre o quê especula; de que coisa [desta ciência] se beneficiará, que mérito alcançará (desta ciência). Deste modo, (a pessoa) se dirige ao que as ciências oferecem com conhecimento e perspicácia e não às cegas e com negligência.

Neste livro, a pessoa terá a possibilidade de comparar as ciências para saber qual é a preferível, mais útil, mais perfeita, mais confiável, mais vigorosa ${ }^{10}$; a mais frágil, a mais débil e a mais carente.

Também se beneficia deste livro, no âmbito do desvelamento do conhecimento, a pessoa que busca o conhecimento numa das ciências [citadas]. Suponhamos, porém, que isto não ocorra: se se questionar sobre o conjunto [do conhecimento] que o livro possui, e sobre a catalogação de suas partes e o conteúdo de cada parte, não haverá embuste quanto a este questionamento $\mathrm{e}$ quanto à camuflagem [de algo].

Ficará evidenciado, também, por alguém que tem conhecimento destas ciências, o seguinte: conhece o conjunto ou algumas partes; (ficará evidente), ainda, a dimensão do conhecimento que possui.

Ademais, se beneficiará deste [livro] quem é educado ${ }^{11}$, quem tem refinamento ${ }^{12}$ e intenciona reunir o conjunto de cada ciência e quem preza a semelhança com a gente da ciência ${ }^{13}$, pois se sentirá como que pertencendo a eles.

\footnotetext{
10 "Mais vigorosa" traduz o termo árabe aqwa. Este termo, neste texto, comporta, também, ser traduzido como "exata", "precisa".

11 "Educado", vale dizer: aquele que recebeu educaçáo numa escola, ensino, adquiriu conhecimentos.

${ }^{12}$ Refinamento quanto ao conhecimento que possui.

13 "Gente da ciência" traduz Ahl al-'ilm, ou seja, pessoas que têm conhecimento das ciências, pessoas cultas nesta área.
} 


\section{TraduÇáo}

\section{SOBRE A CIÊNCIA FÍSICA E A CIÊNCIA METAFÍSICA ${ }^{14}$}

\section{Al-Fārābi}

\section{A CiÊnCIA NATURAL}

A ciência física especula ${ }^{15}$ sobre os corpos naturais e sobre os acidentes que subsistem nesses corpos e faz conhecer as coisas das quais, pelas quais e nas quais estes corpos existem e [faz conhecer] os acidentes que subsistem neles ${ }^{16}$.

Alguns corpos são artificiais e outros naturais. Os artificiais são, [por exemplo], o vidro, a espada e a cama. Em resumo, é tudo aquilo que existe pela arte $^{17}$ e pela vontade do ser humano.

Os [corpos] naturais são aqueles cuja existência não ocorre pela arte e pela vontade do ser humano como, [por exemplo], o céu, a terra e o que há entre eles; as plantas e os animais. E a condição ${ }^{18}$ dos corpos naturais sob este aspecto é igual à condição dos corpos artificias, ou seja: há coisas nos corpos

\footnotetext{
${ }^{14}$ Tradução do capítulo IV da obra Catálogo das ciências (Ihṣā' al- 'Ulūm) de al-Fārābī, considerado um dos mais importantes filósofos do mundo islâmico. Tem como objetivo disponibilizar em língua portuguesa um texto dos mais relevantes de sua época cuja temática abrange os seguintes temas: linguagem e seu ensino, lógica, matemáticas, ciência natural (física), metafísica, ciência política, jurisprudência islâmica e teologia islâmica. Esta traduçáo abarca apenas o capítulo IV que versa sobre ciência natural e metafísica.

"Ciência física” e "ciência metafísica” traduzem 'Ilm al-Ţabī 'ç e 'Ilm al-Ilāhī, respectivamente. O termo "ciência" é utilizado aqui como sinônimo de conhecimento. Assim sendo, pode-se dizer que alFārābī anuncia uma exposição sobre o conhecimento da física (ciência natural) e sobre o conhecimento da metafísica.

15 "Especula" traduz o termo árabe yanzur, relativo à faculdade especulativa.

16 "O objetivo da ciência física são os corpos existentes na natureza ou no mundo; seus acidentes e suas quatro causas: material, formal, final e agente. Essas causas são aquelas que ele [al-Fārābī] indicou [no texto] pelas expressóes 'das quais', 'pelas quais' e 'nas quais'." [Nota do editor do livro Ali Bu Melhem, obra objeto desta tradução (AL-FĀRĀBĪ, 1996, p. 67, nota 1)].

17 "Arte" traduz $\sin \bar{a}^{\prime} a$, isto é, ofício.

${ }^{18}$ Condição ou estado.
} 
artificiais que existem por estes ${ }^{19}$ e estas coisas são mais evidentes nos corpos artificiais do que nos [corpos] naturais.

Os [acidentes] que subsistem nos corpos artificiais ${ }^{20}$ são, por exemplo, o brilho de um tecido, o brilho da espada, a transparência do vidro e o entalhado da cama. E as coisas para as quais existem os corpos [artificiais] são os fins e as intençốes em função dos quais se faz [algo] como, por exemplo, o tecido que foi feito para se vestir, a espada para lutar com o inimigo, a cama para proteger-se da umidade da terra ou para outra coisa em funçáo da qual a cama foi feita e o vidro feito para guardar nele o que se crê que não será transparente em outro recipiente.

Os fins e as intençóes pelas quais existem os acidentes que subsistem nos corpos artificiais como, por exemplo, o brilho do tecido para se embelezar, o lustre da espada para impressionar o inimigo, o entalhado da cama para embelezá-la, e a transparência [do recipiente] de vidro é para fazer visível o que está contido nele.

As coisas em função das quais os corpos artificiais existem são os agentes que fazem existir essas coisas como, por exemplo: o carpinteiro através do qual existe a cama e o artesão que pule e afia $^{21}$ a espada e, [por isso], através dele a espada existe.

$\mathrm{E}$ as coisas pelas quais os corpos artificiais existem são duas em cada corpo artificial como, por exemplo, a espada, cuja existência se dá pelo fio ${ }^{22}$ e pelo ferro. O fio [da espada] é sua figura e sua forma e por elas executa seu ato. $\mathrm{O}$ ferro é a sua matéria e seu sujeito e sustenta sua forma e sua figura [exterior]. A existência do tecido também se dá por duas coisas: pelo fio ${ }^{23} \mathrm{e}$ pelo entrelaçamento e urdidura; sendo o tecido sua figura e sua forma e o fio é o que sustenta o tecido e ele [o fio] é seu sujeito e sua matéria.

\footnotetext{
19 "Estes": os corpos artificiais.

${ }^{20}$ Corrijo o texto de "os corpos naturais" (al-ajsām al-țabi ‘ìyya) para "os corpos artificiais" (al- ajsām al-șinā 'ìyya), pois é o correto de acordo com o exposto no texto.

21 "Pule e afia" traduz o termo árabe șaiqal. Assim é denominado o artesão que faz o polimento e afiação da espada. Cf. (AL-FĀRĀBĪ, 1996, p. 68).

${ }^{22}$ Fio ou gume.

${ }^{23}$ Fio como material têxtil.
} 
A existência da cama também se dá por duas coisas: pela quadratura e pela madeira. A quadratura é sua figura ${ }^{24}$ e sua forma e a madeira é sua matéria e o que sustenta a quadratura.

O mesmo ocorre com outros corpos artificiais. Pela reunião harmônica dessas duas coisas, [forma e matéria], ocorre a existência de cada uma delas em ato e aperfeiçoadamente; e [ocorre] a sua quididade ${ }^{25}$. Ademais, cada uma delas, ou age ou recebe a ação ou é utilizada, ou se recebe benefício dela para o caso em função do qual foi formada ${ }^{26}$ quando sua forma ocorre em sua matéria. Certamente que a espada realiza a sua ação somente enquanto afiada e o tecido é útil somente quando a trama de seus fios está terminada; e o mesmo ocorre com outros corpos artificiais.

Esta também é a disposição dos corpos naturais, pois cada corpo [natural] existe por uma intenção e um fim. Assim também sucede a cada coisa que subsiste nos corpos naturais; existem por uma intenção e por um fim. Ademais, todo corpo e todo acidente tem um agente pelo qual existe. Todo corpo natural existe e subsiste por duas coisas: uma delas, [por exemplo], é o fio da espada que, também, é a forma deste corpo natural. A outra, é o ferro da espada, que é a matéria do corpo natural e seu sujeito, seu substrato e o recipiente de sua forma. Entretanto, a espada, a cama e o tecido, e outros corpos artificiais, podem ser constatados pela visão e pelos sentidos como, por exemplo, o fio da espada e a quadratura da cama e sua madeira. Quanto aos corpos naturais, não conhecemos suas formas e não são sensíveis, a veracidade de suas existências ocorre pelo raciocínio, e pela demonstraçáo correta ${ }^{27}$.

No entanto, há muitos corpos sensíveis que não têm formas sensíveis como, por exemplo, a bebida alcoólica: é um corpo que foi produzido, mas o poder de embriagar não é sensível; no entanto, sabemos de sua existência pela ação de seu efeito. Tal poder é a forma da bebida alcoólica e esta situação da bebida alcoólica de embriagar é a mesma situação do fio da espada, pois através

\footnotetext{
${ }^{24}$ Figura ou forma exterior.

25 "Quididade" traduz o termo árabe māhiya. A quididade é a essência necessária ou substancial de uma coisa.

${ }^{26}$ Foi formada ou ocorreu a forma.

27 "A diferença entre os corpos naturais e os corpos artificiais é que as causas dos primeiros não são sensíveis enquanto as causas dos artificiais é sensível. Com o termo "sensíveis", al-Fārābī quer expressar que são evidentes ou conhecidos. Talvez, em função disso que nós sabemos a partir do quê e o porquê produzimos [algo], e quem o produziu e a configuração que lhe damos. Quanto aos corpos naturais, não sabemos do que foram produzidos, nem o objetivo de quem os produziu nem a causa que os produziu." [Nota do editor (AL-FĀRĀBĪ, 1996, p. 70, nota 1)].
} 
desse poder é que a bebida alcoólica realiza seu ato ${ }^{28}$. $\mathrm{O}$ mesmo ocorre com os remédios produzidos pela medicina como, por exemplo, um antídoto ${ }^{29} \mathrm{e}$ outros [remédios] que agem nos corpos em função do poder da composição dos remédios; e esse poder não é sensível, mas pode ser constatado em função das açôes [resultantes] deste poder. Todo remédio torna-se remédio por duas coisas: pela mistura da composição e pelo poder pelo qual executa sua ação; e as composições são sua matéria e o poder pelo qual realiza sua ação é a sua forma. Se esse poder se aniquilar, náo seria remédio, tal como se se aniquilar o fio da espada, deixa de ser espada e, ainda, como se se do tecido aniquilar a urdidura de seus fios na trama, deixa de ser tecido.

Com esses exemplos é necessário que você entenda a forma e a matéria dos corpos naturais; mesmo que não possam ser constatados pelos sentidos, tornam-se iguais às matérias: através de seus efeitos comprova-se a existência das matérias e das formas nos corpos artificiais. É o exemplo do olho e o poder pelo qual ocorre a visão; o poder da mão e o poder pelo qual pode pegar [as coisas]. E assim ocorre com cada um dos órgáos; pois o poder do olho [de enxergar] não é visto nem se comprova com algum dos efeitos sensíveis posteriores, mas apenas se intelige intelectualmente ${ }^{30}$. E este outro poder que há nos corpos naturais é denominado forma e figura por analogia com as formas dos corpos artificiais ${ }^{31}$, pois a forma, a figura e a conformação [exterior] pretende-se que sejam sinônimos que, entre o senso comum, indicam os tipos dos corpos artificiais. Sendo assim, [esses sinônimos] foram aplicados por analogia aos poderes e às coisas cuja situação nos corpos naturais é a mesma da conformação, das formas e da figura nos corpos artificiais porque, [para as coisas produzidas pelas artes $\left.{ }^{32}\right]$ é costume o senso comum transferir nomes de coisas a [outras] coisas semelhantes. E as matérias dos corpos, suas formas sua causa eficiente e seus fins pelos quais existem, são denominados princípios dos corpos, e se se referem aos acidentes dos corpos, são denominados princípios dos acidentes que estão nos corpos.

A ciência física faz conhecer os corpos naturais de modo que o corpo que existe é evidenciado [concretamente]; e, também, faz conhecer a matéria,

\footnotetext{
${ }^{28}$ Realiza seu ato, ou seja: embriaga.

29 "Antídoto" traduz al-duriāq, antigo preparado farmacêutico de composição complexa e ao qual se atribuía extraordinárias propriedades curativas.

${ }^{30}$ Intelectualmente: pelo intelecto.

${ }^{31}$ Corrijo o texto de "naturais" para "artificiais", pois do contrário, a exposiçấo não teria sentido.

${ }^{32}$ Artes ou ofícios.
} 
a forma, a causa eficiente e o fim para o qual esse corpo existe. Ademais, faz conhecer os acidentes dos corpos e as [substâncias] em que subsistem; suas causas eficientes e os fins pelos quais existem esses acidentes ${ }^{33}$. Esta ciência faz conhecer os princípios dos corpos naturais e os princípios de seus acidentes.

Alguns corpos são simples e outros compostos; os simples são aqueles cuja existência não [ocorre] por intermédio de corpos, e os compostos são aqueles cuja existência [ocorre] através de outros corpos distintos [desses] como, por exemplo, o animal e o vegetal.

\section{A CiÊNCIA NaTURAL SE DIVIDE EM OITO GRANDES PARTES}

Primeira - Análise sobre o que há de comum entre todos os corpos naturais, os simples e os compostos, com relação aos princípios e os acidentes que seguem esses princípios.

Segunda - Análise dos corpos simples; eles existem? Se existem, quais são as suas partes? Qual é o seu número ${ }^{34}$ ? Em seguida, a análise sobre os elementos $^{35}$ dos corpos compostos. Esses [elementos] estão [realmente] nos [corpos] simples cuja existência foi evidenciada ou são corpos distintos procedentes daqueles ${ }^{36}$ ? Se estão naqueles e não sendo possível que procedam daqueles, então, ou é parte deles ou o todo procede daqueles; se é parte [que procede daqueles], entáo, certamente são daqueles [corpos compostos]. Analisa, também, o que é comum entre todos os corpos simples e quais são elementos e princípios dos corpos compostos e quais não são elementos deles ${ }^{37}$, e o que foi catalogado [dos corpos compostos], dos princípios e dos acidentes [dos corpos compostos].

\footnotetext{
33 "Nesta passagem, al-Fārābī define com precisão o tema da ciência natural ao mencionar os princípios dos corpos naturais, querendo se referir com (o termo) princípios às quatro causas." [Nota do editor (AL-FĀRĀBĪ, 1996, p. 72, nota 2)].

${ }^{34}$ Qual é o seu número, quer dizer, quantos são?

35 "Elementos" traduz ustuqusát. O editor do livro faz a seguinte nota: "Ustuqusát é plural de ustuqus, e são os elementos simples pelos quais se formam os corpos compostos que, segundo al-Fārābī, são quatro: fogo, ar, água e terra." (AL-FĀRĀBĪ, 1996, p. 73, nota 1).

36 "Daqueles": dos corpos compostos.

37 "Deles": dos corpos compostos.
} 
Terceira - Análise sobre a geração dos corpos naturais e sua corrupção em geral ${ }^{38}$, e tudo que lhe é inerente, e analisa, ainda, como ocorre a geração dos elementos e como se corrompem e como ocorrem ${ }^{39}$ a partir deles ${ }^{40}$ os corpos compostos e a [respectiva] concessão dos princípios para tudo isto.

Quarta - Analisa os princípios dos acidentes isoladamente ${ }^{41}$ e os efeitos próprios dos elementos sem [considerar as coisas] compostas a partir deles.

Quinta - Especulação sobre os corpos compostos pelos elementos. Alguns destes corpos têm partes semelhantes e outros, partes distintas; alguns [corpos] de partes semelhantes, suas partes compóem os [corpos] de partes distintas como, por exemplo, a carne e o osso; e outros [corpos] de partes semelhantes não podem ser princípio de um corpo natural de partes distintas como, por exemplo, o sal, o ouro e a prata. Especula, também, o que é comum a todos os corpos compostos de partes e, ainda, especula sobre o que é comum a todos [os corpos] compostos de partes semelhantes, sejam suas partes [compostas] de partes distintas ou de outras partes.

Sexta - Especula sobre o que é comum aos corpos compostos de partes semelhantes que não são partes [de corpos] de partes distintas; e estes são: os corpos minerais como, por exemplo, as pedras e suas diversas classes e as diversas classes das coisas minerais e o que é próprio de cada espécie delas.

Sétima - Especulação sobre o que é comum às diversas espécies de plantas e o que é próprio de cada uma das [espécies], e isto é uma das duas partes da especulação sobre [os corpos] compostos de partes distintas.

Oitava - Especula sobre o que é comum às espécies dos animais e o que é próprio de cada espécie, e isto é a segunda parte sobre a especulação sobre [os corpos] compostos de partes distintas.

\footnotetext{
38 “'Geração' e 'corrupçấo' significam a geração dos corpos e sua dissoluçâo. A geração de um corpo ocorre quando a sua forma é determinada pela matéria, e sua corrupçáo ocorre quando a forma abandona a matéria. É este o conceito que Aristóteles afirmou e al-Fārābī seguiu, e, posteriormente, Ibn Sīnā e Ibn Rušd, também seguiram sobre a geração e a corrupção. A matéria é azalīya (eterna, porém no sentido de que não tem começo) e abadìya (eterna, porém no sentido de que não tem fim) e, por isso, nenhuma coisa procede do não-ser ('adam) e nenhuma coisa segue para o não-ser. Tudo que ocorre na natureza relativamente aos corpos e sua corrupçâo, é a aquisiçâo de uma forma pela matéria através de (outra) forma e, posteriormente, abandona essa forma para adquirir uma forma nova." [Nota do editor (AL-FĀRĀBĪ, 1996, p. 73, nota 2)].

39 "Como ocorrem": como ocorre a geração, como se engendram.

40 "Deles": dos elementos.

41 "Isoladamente": só os acidentes, sem considerar algo associado a eles.
} 
A ciência física faz conhecer em cada espécie destes corpos seus quatro princípios e os acidentes que seguem esses princípios. Resumidamente, é isto que há na ciência física e suas partes e o resumo do que há em cada uma de suas partes.

\section{A CIÊNCIA METafísICA}

\section{A CIÊNCIA METAFÍSICA ${ }^{42}$ SE DIVIDE EM TRÊS PARTES}

A primeira [parte] faz uma análise dos existentes enquanto existentes ${ }^{43}$ e as coisas que se lhes apresentam.

A segunda [parte] analisa os princípios das demonstraçôes nas ciências especulativas particulares a qual determina para cada ciência a especulaçáo sobre um existente particular como, por exemplo, a lógica, a geometria, a aritmética e as demais ciências últimas que se assemelham a essas ciências. Analisa, também, os princípios da ciência lógica, os princípios das ciências matemáticas e os princípios das ciências naturais; busca suas verdades e faz conhecer suas substâncias. Analisa as especulaçôes ${ }^{44}$ corrompidas que os antigos ${ }^{45}$ apresentaram sobre os princípios destas ciências como, por exemplo, a especulação dos que acreditavam que o ponto, a unidade, as linhas e as superfícies eram substâncias separadas, e outras especulaçóes semelhantes a estas a respeito dos princípios das outras ciências; especulaçóes estas que, quando analisadas, demonstram que são corrompidas.

A terceira parte analisa as existências que não são $\operatorname{corpos}^{46}$. Por primeiro, analisa se [esses existentes] existem [realmente] ou não. Se se demonstra que existem, então, posteriormente analisa se são muitas ou não. Se se demonstra que são muitas, então, posteriormente, analisa se são finitas ou não. Se se demonstra que são finitas, então, posteriormente, analisa se suas completudes são iguais ou distintas. Demonstra-se que são distintas quanto à completude. Posteriormente demonstra que, tendo em vista que são muitas, elevam-se das menos perfeitas às mais perfeitas, e as mais perfeitas [chegam a um limite de

\footnotetext{
${ }^{42}$ A ciência metafísica ou "sobre o conhecimento da metafísica".

43 "Enquanto existentes": análise dos existentes em si mesmos sem interferência externa.

44 "Especulaçôes" traduz zunūn, relativo à faculdade especulativa.

45 "Dos antigos" se refere aos filósofos da Grécia antiga.

46 "Os existentes que não são corpos e não estão em corpos, como, por exemplo, Deus e os intelectos segundos, o intelecto agente, a alma, etc." [Nota do editor (AL-FĀRĀBĪ, 1996, p. 76, nota 1)].
} 
perfeição] que termina ${ }^{47}$ em uma [existência] tão completa que não é possível que alguma coisas seja mais completa do que [esta existência] e não há uma coisa que seja o fundamento ou causa semelhante ao grau de sua existência; não tem igual nem contrário; e, até chegar ao primeiro, não há nada anterior a ele, e não há nenhuma coisa que o preceda e, enquanto existente, não é possível que adquira sua existência [a partir] de outra coisa. Este único é o primeiro e o antecessor absoluto em sua unidade. [Esta parte] também demonstra que os outros existentes sáo posteriores a ele quanto à existência; ele é o existente primeiro e concede a existência a todos os outros seres exteriores a ele; ele é o único, o primeiro, e concede a unidade a cada coisa. Ele, também, é a verdade que concede a verdade a cada ser que tem verdade e, também, o modo ${ }^{48}$ pelo qual concedeu isto. [Demonstra] também, que náo é possível, em princípio, que haja multiplicidade nele sob nenhum aspecto; ele é, pelo nome e pelo significado, o mais merecedor da unidade e da existência, é mais verdade do que qualquer coisa externa a ele que se denomina una, [seja um] existente ou [uma] verdade externos a ele. Ademais, demonstra que aquele que tem essas qualidades, é necessário crer que é Deus, Todo-Poderoso, santificados sejam Seus Nomes ${ }^{49}$. Depois disso explica o significado dos outros [atributos] com os quais Deus é descrito até enumerar todos e dá a conhecer como os existentes começaram a existir a partir Dele e como lhes foram concedidas as existências a partir Dele.

[Esta parte] também analisa os graus das existências e como lhes ocorreram estes graus e por qual coisa cada uma [das existências] merece o grau em que se encontra, e demonstra o modo da relação de uma com a outra e sua harmonia e por qual coisa ocorrem esta relaçáo e harmonia. Ademais, segue [explicando] sobre os significados das açóes de Deus, Todo-Poderoso, nas existências até enumerar todas e esclarece ${ }^{50}$ que nessas ações não há injustiça, nem deficiência nem dúvida, nem desordem, nem obra imperfeita; em suma, em princípio, não há imperfeição em algo [dessas ações].

Continuando, refuta as opiniốes corrompidas a respeito das açôes de Deus, Todo-Poderoso, nas quais não há imperfeição, e, também, não há imperfeição em Deus e nas existência que criou, refutando todas [as opinióes

\footnotetext{
${ }^{47}$ Termina ou que tem como fundamento.

48 "Modo" traduz a palavra jiha; pode ser modo ou aspecto.

49 "Nomes" traduz asmäuh; literalmente, "Seus Nomes". Por se referir a Deus no âmbito da doutrina islâmica, pode-se entender como sinônimo de atributos de Deus.

50 "Esclarece": deve-se ter em conta que "esta parte esclarece", ou seja, a ciência metafísica.
} 
corrompidas] com provas que beneficiem a ciência verídica cuja ciência o ser humano não pode ter dúvida alguma nem suspeitar, e, em princípio, não é possível que se afaste $[\text { disso }]^{51}$.

AL-FĀRĀBĪ. On physical science and metaphysical science. Introduction, translation and notes by Jamil Ibrahim Iskandar. Trans/Form/Ação, Marília, v. 42, p. 391-404, 2019. Edição Especial.

\section{REFERÊNCIAS}

AL-FĀRĀBĪ. Ihıăa al-'Ulüm. (Catálogo das ciências). Edição, apresentação, comentário explicativo e divisão dos capítulos de Ali Bu Melḥem. Beirute: Dār al-Hilāl, 1996.

AL-FĀRĀBĪ. Las filosofias de Platón y Aristóteles. Traducción, introducción y notas: Rafael Ramón Guerrero. Madrid: Ápeiron Ediciones, 2017.

CRUZ HERNÁNDEZ, M. Historia del pensamiento en el mundo islámico. V. 1 - Desde los orígenes hasta el siglo XII en Oriente. Madrid: Alianza Editorial, 1996.

FAKHRY, M. Al-Färäbī, founder of Islamic Neoplatonism: his life, works and influence. Oxford: Oneworld, 2002.

ISKANDAR, J. I. Introdução. In: AVICENA (IBN SĪNĀ). A origem e o retorno. Introdução e aparelho crítico: Jamil Ibrahim Iskandar. São Paulo: Martins Fontes, 2005. p. XXIII-XXXIII.

\footnotetext{
51 "Não é possível que se afaste disso": não é possível que se se afaste do que foi exposto neste parágrafo, dos conceitos expostos.
}

Recebido: 30/12/2019

Aceito: 30/12/2019 
AL-FĀRĀBİ; ISKANDAR, J. I. 